Original Research

\title{
Sustainability and Economic Feasibility through the Production of Oyster Mushroom (Pleurotus Ostreatus (Jacq.) P. Kumm.) Derived from the Waste of Coffee-Industry: A Case Study in the Western Area of San Salvador, El Salvador
}

\author{
Juan Carlos Calderon Lopez ${ }^{1,2 *}$, Sarawut Thepanondh ${ }^{2}$, Harin Sachdev ${ }^{3}$, \\ Alma Maria Palencia Avelar ${ }^{4}$, Marlene Cruz del Carmen Leon ${ }^{4}$ \\ ${ }^{1}$ Ratchasuda College, Mahidol University, Nakhon Pathom 73170, Thailand \\ ${ }^{2}$ Faculty of Public Health, Department of Sanitary Engineering, Mahidol University, Bangkok 10400, Thailand \\ ${ }^{3}$ Faculty of Environment and Resource Studies, Mahidol University, Nakhon Pathom 73170, Thailand \\ ${ }^{4}$ Faculty of “Agricultura e Investigación Agrícola”, José Matías Delgado University, El Salvador
}

Received: 15 December 2020

Accepted: 10 April 2021

\begin{abstract}
This research aims to assess the sustainability and feasibility of the production of Pleurotus ostreatus using ground coffee seed and pulp waste as substrate, and then demonstrating its economic profitability. Different raw materials were characterized as substratum and technical aspect production in the greenhouse for $P$. ostreatus were analyzed with the economic analysis for financing the project. With this technique, we found an option of sustainable model production, which concedes added value to the agricultural wastes from coffee processing once is used as a source of substrates for the production of Pleurotus ostreatus. The results obtained from the production of mushrooms through the waste from ground coffee and pulp are feasible and profitable in San Salvador. The use of coffee waste in the production of mushrooms will reduce the waste or biomass resulting from the coffee industry, therefore, it is a sustainable alternative in environmental terms. Moreover, economic analyses from PI's were 3.047052287 , given that it was $>1$, consequently, the project was accepted, while the IRR was $51.47 \%$ per year, that is $\$ 0.52$ which is recovered for every dollar invested. Hence, in terms of financial
\end{abstract}

*e-mail: juancarlos.cal@mahidol.edu jccarloscalderon@gmail.com 
analyses, it is believed that mushroom production is economically profitable and environmentally sustainable.

Keywords: economic viability, coffee grounds waste, coffee pulp, pollution reduction, sustainable agriculture

\section{Introduction}

The agriculture technology of edible mushroom production has been increasing in El Salvador due to the feasibility of planting in recent years, in different types of substrates, mainly those are obtained from agricultural waste such as the use of "corncob" for being a great source of cellulose, which helps to improve the growth and development of mushroom. This type of substrate is obtained from the cultivation of corn. In addition, sustainable agriculture proposes long-term alternatives in viable economic aspects that improve the quality of life of the producer and society in general, without altering the environmental quality. Funding and inversion of the project are determined through the techno-economic analysis. Furthermore, El Salvador since the last decades has promoted programs aimed at genetic, planting, and sustainable improvement in coffee production, this includes associated crops production of mushrooms [1]. By using this technique, the production of Pleurotus Ostreatus benefits the environment because it encourages the implementation of mitigation and compensation strategies [2]. Moreover, in this research, the use of waste from pulp and ground coffee from the coffee industry is proposed. El Salvador has been characterized as a country that produces high quality coffee. According to B. Kilian, the sustainable certification processes on coffee have brought several benefits to the Latin America producers, as well as Central America, where Costa Rica and El Salvador are recognized for their high/strict altitude coffee plantation and cup of excellence. It can be assumed that a big part of the higher price premiums, achieved in these countries are due to their well-known high-quality coffee [3]. Furthermore, taking into consideration that the consumption of mushrooms improves health and quality of life due to its nutritional contributions $[4,5]$.

Furthermore, coffee products are exported, including other sub-products thereof, with added value for subsequent sale abroad at a much higher price. One of these sub-products is the waste that is obtained through the agro-industry process of the coffee plantation. The reuse of these wastes is allowed to be valued, therefore, the coffee farms can take advantage of these resources [6]. The solid waste from the coffee agro-industry can be used for other purposes, for instance source of compost, substrate, biodiesel products and its by-products [710]. All these wastes obtained during the agro-industry process activity cause an adverse environmental impact if they are thrown into natural sources of water. Therefore, the cultivation of edible mushrooms as Pleurotus ostreatus, could be an alternative to mitigate and compensate the pollutants from the agroindustry of coffee and it can help to increase economic profitability. There are different environmental impacts arising at different stages of the life cycle of the coffee agroindustry. It was found that coffee cultivation is a significant contributor for ecosystem damage in all brewing scenarios, particularly on land-use related midpoint indicators [11, 12]. The technology applied to the cultivation of edible mushrooms allows earning large productions in relatively little space. Moreover, the production of $P$. ostreatus is presented as an alternative from an economic, social and environmental point of view for the management and use of agroindustry waste, environmental protection and employment generation, which fits well in the sustainable model contexts. In addition, giving added value to solid waste, which is obtained from the coffee agro-industry, can generate extra income for producers. Further to this, international markets are interested in by-products from Oyster mushroom because it possesses excellent nutritional and medicinal qualities. Sustainable mushroom farming does not have to be complicated or expensive. Oyster mushrooms can be grown indoors on pasteurized corn stalks, wheat and a wide range of other materials including paper and pulp by-products, can also be grown on hardwood stumps and logs. The waste substrate from Oyster production is useful as fodder for cows, chickens, and pigs. Therefore, this is a sustainable production alternative which increases the economy and protects the environment impact especially from the coffee waste industry [13-15]. The fruiting bodies of the Pleurotus ostreatus, which are the edible parts, are an excellent source of good quality protein, this is because, in their content, all essential amino acids are presented where the predominant are alanine, glutamic acid, and glutamine [16].

In addition to this, the National Center for Agricultural and Forestry Technology, (CENTA), and Tottori University, Japan conducted an investigation in 2009 to 2013 where they mapped the production of mushrooms in El Salvador highlighting 12 places primarily in mountain range, volcano area, and mountains of El Salvador, where 1240 specimens were collected and 101 species were identified, however, the investigation confirmed that the agricultural production of $P$. Ostreatus has not intensified [17]. The production and market of mushrooms is still growing and there is a niche market segment. Also, The Regional Network Program for the support of associations of small coffee 
producers in Central America and the Caribbean involves six countries: Guatemala, Dominican Republic, El Salvador, Honduras, Costa Rica, and Nicaragua. Therefore, this case study aims to improve the quality of life of small coffee producers in rural areas, as well as, communities in mountainous regions, in order to produce quality coffee in terms of sustainability and implement the diversification of crops or polycultures in association with the coffee.

\section{Methodology}

\section{Study Area}

A reconnaissance of the mountainous regions was carried out, it was taken into consideration the mapping carried through by the University of Tottori, Japan, and The National Center for Agricultural and Forestry Technology [18] where they describe that the altitudes range from 800 to 2418 meters above sea level is basically favorable for the reproduction of mushroom in El Salvador, as well as other important climatic factors which affect the natural growth, below we present the mushroom biodiversity map in El Salvador (Fig. 1).

Evidently, there is a great diversity of mushroom. Moreover, is clear is that fungi kingdom play a really important role in the functioning of ecosystems. [19, 20] In addition to recycling nutrients and helping plants and crops grow efficiently, fungi provide us with compounds that produce antibiotics, statins to treat cholesterol, and immunosuppressant. [21] Moreover, some fungi (endophytes and mycorrhizae) can help plants respond to stresses such as increased temperatures and drought. Advances in its agricultural applications could translate into improved food security, environmental sustainability and increased production income, as is the case in this case study. [22, 23]

Further, in accordance with the mapping by the University of Tottori, Japan, and CENTA the biodiversity found through actualization and identification of varieties such as: Auricularia auricula-judea, Cookeina speciosa, Amanita jacksonii, Pseudohydnum gelatinosum, Cookeina tricholoma, Geastrum sp. Pleurotus Ostreatus, Ganoderma sp., and Agaricus sp., which are growing naturally in salvadoran flora (Fig. 2).

Therefore, the municipality of San Martin was chosen as a case of study, which is situated in the department of San Salvador approximately 800 meters above sea level and it is located in the western area of San Salvador and bordered on the north by San José Guayabal. As anteriorly reported, this research examined two main components of the project, i.e., its sustainability and its financial-economic feasibility. The production of oyster mushroom (pleurotus ostreatus (jacq.) p. kumm.) from the organic waste derived from the coffee processing, involved the construction of two greenhouses. The project size was established on the construction of two greenhouse galleries with the specific requirements and cost, furthermore, for the first phase, it is designated to produce an arroba per

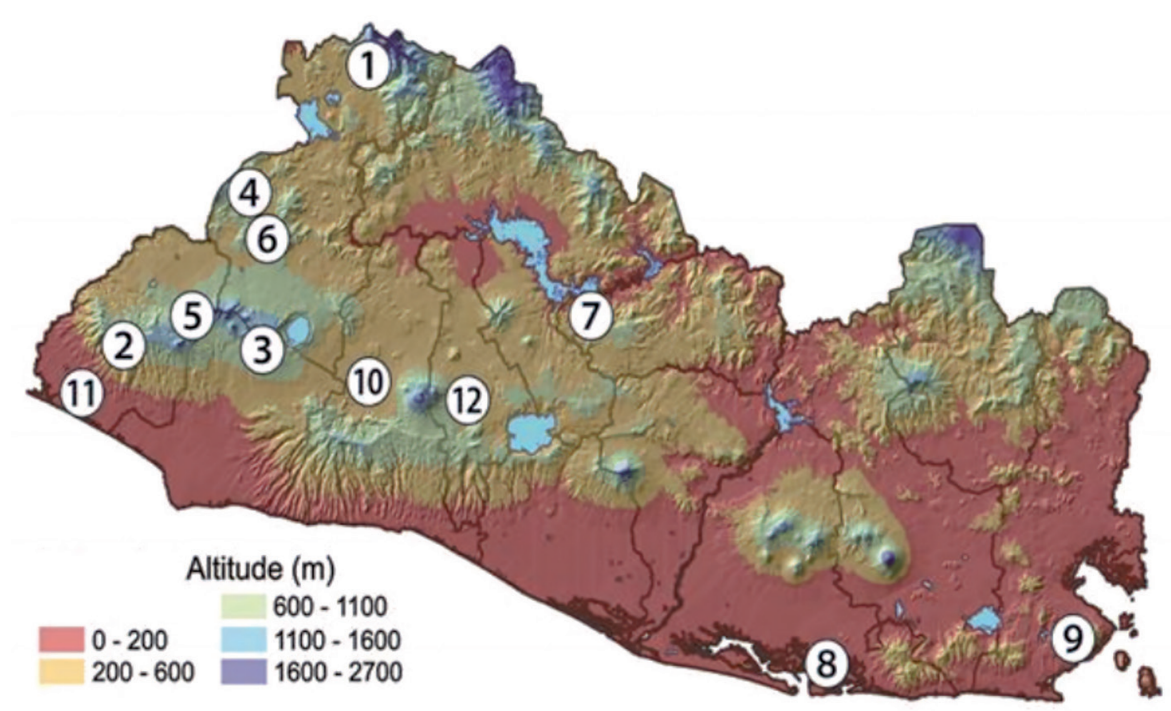

(1) National Park Montecristo, (2) National Park El imposible, (3) National Park Cerro Verde

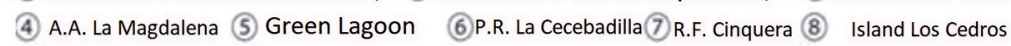
(9) M.A. Conchagua (10) Valley Zapotitấh) P.A. Santa Rita (12) San Salvador

Abbreviation: (A.A.) Agricultural Area (P.R.) Peak Range (R.F.) Rain-Forest (M.A.) Mountain Area (P.A.) Protected Area

Fig. 1. The Mushroom biodiversity map in El Salvador. This map describes the production of Mushrooms depending on the favorable altitude and area of El Salvador. 
a)

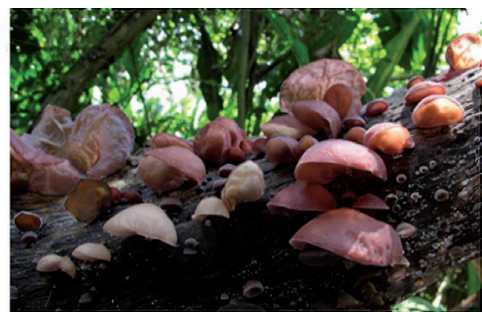

d)

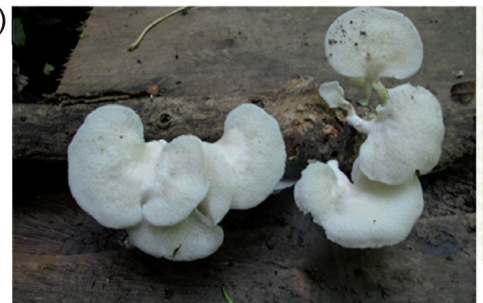

g)

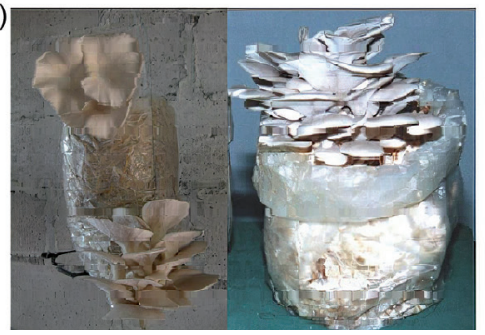

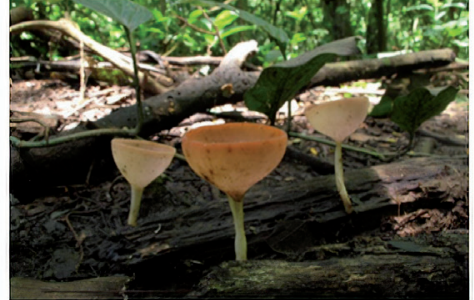

e)

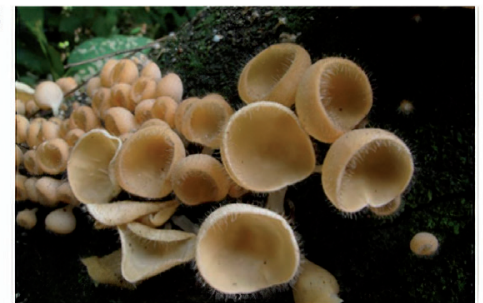

h)

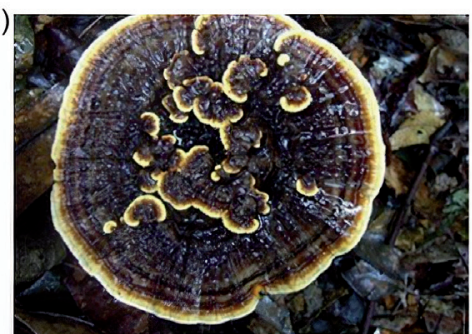

c)

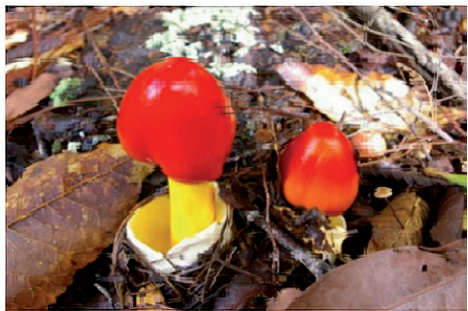

f)

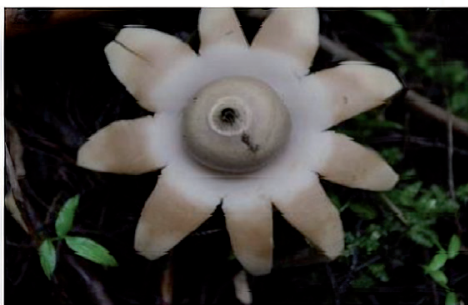

i)

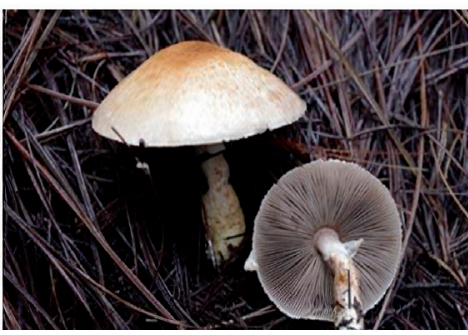

Fig. 2. Examples of Mushrooms varieties in the Salvadoran flora.

day. Moreover, the dimensions for both greenhouses we describe below: five meters long and three and a half wides. The useful life of the greenhouses with good maintenance is approximately a six-year lifespan $[24,25]$. Moreover, the cost of the greenhouses were US dollar (\$) 962.00 which covers the installment and construction. The altitude, humid, warm climate and subtropical forest are favorable conditions for the natural development of these mushrooms. According to the lag-period method on the operation cost, the working capital was quantified.

\section{Costs Calculations: $\mathrm{TC}=\mathrm{FC}+\mathrm{VC}$}

...where Total Cost (TC), is equal to Fixed Cost (FC) plus Variable Cost (VC), furthermore, the total variable cost (TVC) and breakeven point (BEP) were used. Moreover, the NPV and IRR were taken into consideration from Boateng and Baker [26-28]. The Total variable cost was divided by the number of units produced, which remainder will be the unit variable cost, as following:

$$
N P V=\sum_{n=0}^{N} \frac{C_{n}}{(1+r)^{n}}=O
$$

...where:

$\mathrm{C}_{\mathrm{n}}=$ Net Cash Flow, successively every year.

$\mathrm{N}=$ Years of the Project.

$\mathrm{r}=$ The discount rate.

$\mathrm{O}=$ Net Expenses.
In order to obtain " $\mathrm{C}$ " the mathematical operation is subtracting from the incomes the expenses, this means that the total income for years, will be subtracted by: (operating expenses, administration, sales, financial, taxes of law). From this operation, Net Income will be left as a result $[29,30]$

As a consequence, $\mathrm{C}_{\mathrm{n}}=$ Net Cash Flow subsequently every year. Further, $\mathrm{N}=$ years of the Project; the number of cash flows (in this case, the project period, is seven years; consequently, is considering annual cash flows, then the number would be 7). $r=$ the discount rate (as this case, 7\%). Net Expenses is equal to $\mathrm{O}=$ Investment activities minus Working Capital plus Financial Activities.

To calculate $I R R$, it is necessary to obtain certain values first such. Therefore, the following formula below is:

$$
I R R=\sum_{t-1}^{T} \frac{C_{t}}{(1+r)^{t}}-C_{0}
$$

...were:

$C_{\mathrm{t}}=$ Net Cash Inflow During the Period t.

$\mathrm{r}=$ "Discount Rate."

$\mathrm{t}=$ "Number of Time Periods."

$C_{0}=$ "Total Initial Investment Cost."

In order to take some decisions in the project, the use of the "Profitability Index" it is necessary, therefore, to calculate it the follow formula is: $[31,32]$ 


$$
P I=\frac{\sum_{t=1}^{n} \frac{C F_{t}}{(1+r)^{t}}}{I}
$$

...where if:

Profitability Index is higher than 1, the project is accepted - $(P I>1)$ is Accepted

Profitability Index is equal 1 , it is indifferent - $(P I=1)$ is Indifferent

Profitability Index is less than 1, the project is rejected - $(P I<1)$ is Rejected

Finally, if the product is accepted it is important to take into consideration the commercial demand, assuming that the product can favor the national economy where it is produced. [33]

\section{Results and Discussion}

This section describes and gives details an explanation of the results obtained from the sustainable alternative, technical and financial evaluation of the implications of carrying out this project. Distinct processes were involved, such as those used for the production and characterization of raw materials, the equipment, and machinery used, it is very important to emphasize that the substrate used for the production of mushrooms is merely organic sources of unused biomass that practically end up in garbage without giving it an added value or alternatives of agro-industrialization. It also explains how the distribution of the plant was defined and the specifications of the civil works, among other aspects of interest in order to prevent possible failures in the effective implementation of the project.

Moreover, this project is focused on the sustainable production of oyster mushrooms using ground coffee seed and pulp as a substrate, resulting from the industrialized waste of coffee production as an innovative solution for the use of the biomass waste from the agro-industry which avoids environmental pollution. In addition, it generates social, economic and environmental gains besides being an alternative to mitigation and compensation impact. Further, oyster mushrooms do not need a particular type of soil to be cultivated, basically, it need an optimal space to grow properly; the spaces must be clean, dry, very well ventilated, and small enough to be controlled, such as greenhouses or other small structures with roofs, as long as there is a good distribution of the place, where the areas must be separated from each other to avoid contamination or mishandling of the raw material.

\section{Technical Evaluation}

The process started using an organic substrate, which was made from coffee pulp and ground coffee seed (residues). Subsequently, the substrate was deposited in water with hydrated lime (calcium oxide) for approximately 12 hours, later on, the substrate was removed to the container with water, in order to drain and cool. Afterward, the inoculum distribution process was carried out, as result, the mycelium grew up in the substrate from ground coffee and pulp, this process is called "sowing". Subsequently, the inoculated substrate was settled for sowing in $5 \mathrm{~mm}$ plastic bags of approximately 25 pounds. Afterward, the bags were transported to the "growing room" or "incubation rooms". In this stage the temperature must be maintained at $24^{\circ} \mathrm{C}$, during 15 days approximately, eventually, the bags were transferred to the place of production. It is emphasized that before starting the process, the spores must be inoculated from the pure Pleurotus ostreatus mycelium, this contributes with success in all stages of $P$. Ostreatus production, and reduce the financial loss. The production process is conformed by eight stages which are described below:

1. To combine and weigh, the pulp and ground coffee seed were weighed in a ratio of three parts.

2. To repose, the compost were stirred daily or by lapses of three days (fermentation).

3. To sterilize, the compost was deposited in a room with isolated walls, which was controlled by temperatures for a period of 24 hours. Subsequently, it was subjected to a pasteurization process for six to eight hours and then cooled at 20 to $26^{\circ} \mathrm{C}$.

4. To distribute, the seeds were spread with a dispenser or manually on the compost (sowing).

5. To fill, the compost was moved in plastic bags with an average size of $1 \mathrm{~kg}$.

6. To transfer, the bags were transported to the incubation area.

7. To control, during two weeks, the humidity and temperature were monitored through the hygrometer at $22^{\circ} \mathrm{C}$.

8. To propagate, the bags were transported to the production hall for the proliferating stage (fruiting).

The pasteurization process lasted six to eight hours and then it was cooled to 20 to $26^{\circ} \mathrm{C}$; the spores of Pleurotus ostreatus were sown and the fertilizer produced was applied. Subsequently, were transported from the bags which contained the sown spores. Afterwards, the bags were moved to the incubation area where the temperature and humidity were monitored until achieved $100 \%$ colonization. Finally, the bags were transported to the production room for the fructification scenario under controlled temperature conditions between 20 to $24^{\circ} \mathrm{C}$.

For the execution and implementation of this project in the municipalities of Santa Tecla and Antiguo Cuscatlán belonging to the Republic of El Salvador, it was necessary first, to identify the market segment, which were interested in the production of mushrooms with the technique using the waste from coffee industry as substrate. Thus, by obtaining 100\% of the sprouted mushroom, it could lead to support the research and break paradigms regarding the viability of coffee residues which were used as a substrate for mushroom production. With the implementation of 
this agro-industrial project; the agricultural sustainability for the Moreover, the cultivation of oyster mushroom implies mitigation and compensation impacts measurables besides its contribution to the world food security that is more and more insufficient, as it is the case of third world countries like El Salvador; at the same time it promotes the sustainability of other resources for the production of the products like the land and the water, products of high agricultural demand that when using this methodology of obtaining the mushrooms it favors the sustainable management of the natural resources; It can satisfy the needs of present and future generations of the products that are being obtained, given the case of the mushrooms.

It has been demonstrated that the production of mushrooms from the pulp and ground coffee waste is possible and very profitable in the long term, not only economically, but it is also very sustainable for the environment since it mitigates the contamination of the waste through the recycling of the same. This alternative is very reliable for those markets interested in acquiring this type of food, as was seen in the research, in addition, it is known that there is very little supply of this product.

\section{Financial Evaluation}

The market for mushroom production is profitable according to the niche studies that were carried out in the research for the project. According to data from the Foundation for Technological Innovation (FIAGRO), by 2013 there will be wholesale sales of fresh mushrooms in supermarkets $(75 \%$ of mushroom consumption nationally) and processed mushrooms in supermarkets and pizzerias (56\% and 38\% respectively). This market for mushroom production can improve in the coming years if it is given the appropriate monitoring and investment for the acceptance of this product. In El Salvador, mushroom seed imports in 2019 amounted to US\$17,860.00 (BCR, 2019), a figure that, according to the high demand from restaurants, supermarkets and canteens in the well-known gourmet markets, has tended to increase in recent years, which favors mushroom growers in the country.

\section{Determination of Financial Needs}

First, it is necessary to analyze the initial investment, the availability of equity, liquidity or short-term availability, which could be converted into equity to finance the initial investment. Moreover, the short-term returns of the project will allow covering the monthly payment of the loan.

The establishment of project resources will come from the company itself and from the income and expenditure budgets, where surpluses of operations are achieved. The discrepancy or missing between the total of the investment and the total of the own resources will be the financial needs of the project.
Initial investment:
$\$ 36,421.70$
Bank loan:
$\$ 7,500.00$
Own funds:
$\$ 28,921.70$
Rate:
$9.25 \%$
NPER
Year Payment
$\$ 1,502.70$

The NPER is a function which returns the number of periods for an investment based on an interest rate and a constant payment schedule as showing in the following table (Table 1).

\section{Financial Evaluation by Net Present Value (NPV) and Internal Rate of Return (IRR)}

For the realization and calculation of the Net Present Value, it is necessary to make the sales budget for the first year of operations. (Table 2, Table 3 and Table 4).

From the chart Annual Sales Budget, which serves to project an increase in the future, annual sales of 3\% every year. Moreover, taking into consideration the credit time of the loan from the bank it's planned for 7 years, therefore the minimum duration for this project will be seven years.

Therefore, for the realization of this exercise, the MARR, IRR, and NPV was obtained through Microsoft

Table 1. Payment, interest and remaining balance per year of the loan from the bank.

\begin{tabular}{|c|c|c|c|c|}
\hline PERIOD & Payment & Interest & Capital & Remaining balance \\
\hline 0 & & & & $\$ 7,500.00$ \\
\hline 1 & $\$ 1,502.70$ & $\$ 693.75$ & $\$ 808.95$ & $\$ 6,691.05$ \\
\hline 2 & $\$ 1,502.70$ & $\$ 618.92$ & $\$ 883.78$ & $\$ 5,807.27$ \\
\hline 3 & $\$ 1,502.70$ & $\$ 537.17$ & $\$ 965.53$ & $\$ 3,784.74 .74$ \\
\hline 4 & $\$ 1,502.70$ & $\$ 447.86$ & $\$ 1,054.84$ & $\$ 2,634.48$ \\
\hline 5 & $\$ 1,502.70$ & $\$ 350.29$ & $\$ 1,152.41$ & $\$ 1,375.47$ \\
\hline 6 & $\$ 1,502.70$ & $\$ 243.69$ & $\$ 1,259.01$ & $\$ 0.00$ \\
\hline 7
\end{tabular}


Table 2. Annual Sales Budget.

\begin{tabular}{|c|c|c|c|c|c|c|c|c|c|c|c|c|}
\hline & \multicolumn{10}{|c|}{ Annual Sales Budget } \\
\hline & Jan & Feb & Mar & Apr & May & Jun & Jul & Aug & Sep & Oct & Nov & Dec \\
\hline Sales projections & 3937 & 3937 & 3937 & 3937 & 3937 & 3937 & 4725 & 4725 & 4725 & 4725 & 4725 & 4725 \\
\hline Cash sales (40\%) & 1574.8 & 1574.8 & 1574.8 & 1574.8 & 1574.8 & 1574.8 & 1890 & 1890 & 1890 & 1890 & 1890 & 1890 \\
\hline Sales to credit (60\%) & 2362.2 & 2362.2 & 2362.2 & 2362.2 & 2362.2 & 2362.2 & 2835 & 2835 & 2835 & 2835 & 2835 & 2835 \\
\hline Total sales & $\mathbf{3 9 3 7}$ & $\mathbf{3 9 3 7}$ & $\mathbf{3 9 3 7}$ & $\mathbf{3 9 3 7}$ & $\mathbf{3 9 3 7}$ & $\mathbf{3 9 3 7}$ & $\mathbf{4 7 2 5}$ & $\mathbf{4 7 2 5}$ & $\mathbf{4 7 2 5}$ & $\mathbf{4 7 2 5}$ & $\mathbf{4 7 2 5}$ & $\mathbf{4 7 2 5}$ \\
\hline
\end{tabular}

Table 3. Annual cash flow (Financial Net Flow).

\begin{tabular}{|c|c|c|c|c|c|c|c|c|c|c|c|c|}
\hline & \multicolumn{10}{|c|}{ Cash flow } \\
\hline & Jan & Feb & Mar & Apr & May & Jun & Jul & Aug & Sep & Oct & Nov & Dec \\
\hline Cash sales & 1574.8 & 1574.8 & 1574.8 & 1574.8 & 1574.8 & 1574.8 & 1890 & 1890 & 1890 & 1890 & 1890 & 1890 \\
\hline Accounts receivable & 2362.2 & 2362.2 & 2362.2 & 2362.2 & 2362.2 & 2362.2 & 2362.2 & 2835 & 2835 & 2835 & 2835 & 2835 \\
\hline$(+)$ Loans & 7500 & 0 & 0 & 0 & 0 & 0 & 0 & 0 & 0 & 0 & 0 & 0 \\
\hline Total cash income & 11437 & 3937 & 3937 & 3937 & 3937 & 3937 & 4252.2 & 4725 & 4725 & 4725 & 4725 & 4725 \\
\hline Production costs & 727.5 & 727.5 & 727.5 & 727.5 & 727.5 & 727.5 & 836.63 & 836.63 & 836.63 & 836.63 & 836.63 & 836.63 \\
\hline Administrative expenses & 1844 & 1844 & 1844 & 1844 & 1844 & 1844 & 1844 & 1844 & 1844 & 1844 & 1844 & 1844 \\
\hline Tax payment & 308.1 & 308.1 & 308.1 & 308.1 & 308.1 & 308.1 & 359.62 & 477.82 & 477.82 & 477.82 & 477.82 & 477.82 \\
\hline Total cash outflows & 2879.6 & 2879.6 & 2879.6 & 2879.6 & 2879.6 & 2879.6 & 3040.3 & 3158.5 & 3158.5 & 3158.5 & 3158.5 & 3158.5 \\
\hline Net economic flow & 8557.4 & 1057.4 & 1057.4 & 1057.4 & 1057.4 & 1057.4 & 1212 & 1566.6 & 1566.6 & 1566.6 & 1566.6 & 1566.6 \\
\hline Debt service & 133.1 & 133.1 & 133.1 & 133.1 & 133.1 & 133.1 & 133.1 & 133.1 & 133.1 & 133.1 & 133.1 & 133.1 \\
\hline Financial Net Flow & $\mathbf{8 4 2 4 . 3}$ & $\mathbf{9 2 4 . 3}$ & $\mathbf{9 2 4 . 3}$ & $\mathbf{9 2 4 . 3}$ & $\mathbf{9 2 4 . 3}$ & $\mathbf{9 2 4 . 3}$ & 1078.9 & 1433.5 & 1433.5 & 1433.5 & 1433.5 & 1433.5 \\
\hline
\end{tabular}

Table 4. Annual cash flow (Flow Net Profit).

\begin{tabular}{|c|c|c|c|c|c|c|c|c|c|c|c|c|}
\hline & \multicolumn{12}{|c|}{ Cash flow } \\
\hline & Jan & Feb & Mar & Apr & May & Jun & Jul & Aug & Sep & Oct & Nov & Dec \\
\hline Total sales & 3937 & 3937 & 3937 & 3937 & 3937 & 3937 & 4252 & 4252 & 4725 & 4725 & 4725 & 4725 \\
\hline $\begin{array}{l}\text { (-) production } \\
\text { costs }\end{array}$ & 727.5 & 727.5 & 727.5 & 727.5 & 727.5 & 727.5 & 836.63 & 836.63 & 836.63 & 836.63 & 836.63 & 836.63 \\
\hline Gross profit & 3209.50 & 3209.50 & 3209.50 & 3209.50 & 3209.50 & 3209.50 & 3415.37 & 3415.37 & 3888.37 & 3888.37 & 3888.37 & 3888.37 \\
\hline $\begin{array}{c}\text { Selling and } \\
\text { administrative } \\
\text { expenses }\end{array}$ & 1844 & 1844 & 1844 & 1844 & 1844 & 1844 & 1844 & 1844 & 1844 & 1844 & 1844 & 1844 \\
\hline $\begin{array}{c}\text { Financial } \\
\text { services }\end{array}$ & 133.1 & 133.1 & 133.1 & 133.1 & 133.1 & 133.1 & 133.1 & 133.1 & 133.1 & 133.1 & 133.1 & 133.1 \\
\hline $\begin{array}{c}\text { Operational } \\
\text { utility }\end{array}$ & 1232.40 & 1232.40 & 1232.40 & 1232.40 & 1232.40 & 1232.40 & 1438.27 & 1438.27 & 1911.27 & 1911.27 & 1911.27 & 1911.27 \\
\hline Interests & 0 & 0 & 0 & 0 & 0 & 0 & 0 & 0 & 0 & 0 & 0 & 0 \\
\hline $\begin{array}{l}\text { Utility before } \\
\operatorname{tax}\end{array}$ & 1232.4 & 1232.4 & 1232.4 & 1232.4 & 1232.4 & 1232.4 & 1438.5 & 1438.5 & 1438.5 & 1438.5 & 1438.5 & 1438.5 \\
\hline Income tax & 308.1 & 308.1 & 308.1 & 308.1 & 308.1 & 308.1 & 359.62 & 359.62 & 359.62 & 359.62 & 359.62 & 359.62 \\
\hline Flow Net profit & 979.93 & 924.30 & 924.30 & 924.30 & 924.30 & 924.30 & 1078.85 & 1433.45 & 1433.45 & 1433.45 & 1433.45 & 1433.45 \\
\hline
\end{tabular}


Excel using the "Formula"; followed by the icon "Financial", category IRR and NPV as shown in the following tables (Table 5, Table 6 and Table 7).

Net Present Value (NPV).

To calculate NPV it is necessary to obtain first certain values. Therefore, the following formula below is:

Table 5. MARR, IRR and NPV.

\begin{tabular}{|c|c|}
\hline MARR $\quad$ (Minimum Acceptable Rate of Return) & $7.00 \%$ \\
\hline IRR $\quad$ (Internal Rate of Return) & $52 \%$ \\
\hline NPV $\quad$ (Net Present Value) & $\$ 57,247.11$ \\
\hline
\end{tabular}

Table 6. Net Income of the Project.

\begin{tabular}{|c|c|c|c|c|c|c|c|c|}
\hline Period of Time (years) & $\mathbf{0}$ & 1 & 2 & 3 & 4 & 5 & 6 & 7 \\
\hline Income & & $\$ 51,972.00$ & $\$ 53,531.16$ & $\$ 55,137.09$ & $\$ 56,791.21$ & $\$ 58,494.94$ & $\$ 60,249.79$ & $\$ 62,057.29$ \\
\hline \multicolumn{9}{|l|}{ Expenses } \\
\hline Operations & & $\$ 8,736$ & $\$ 8,998$ & $\$ 9,268$ & $\$ 9,546$ & $\$ 9,832$ & $\$ 10,127$ & $\$ 10,431$ \\
\hline Administrative & & $\$ 14,208$ & $\$ 14,634$ & $\$ 15,073$ & $\$ 15,525$ & $\$ 15,991$ & $\$ 16,471$ & $\$ 16,965$ \\
\hline Sales & & $\$ 7,920$ & $\$ 8,158$ & $\$ 8,402$ & $\$ 8,654$ & $\$ 8,914$ & $\$ 9,181$ & $\$ 9,457$ \\
\hline Financial & & $\$ 694$ & $\$ 619$ & $\$ 537$ & $\$ 448$ & $\$ 350$ & $\$ 244$ & $\$ 127$ \\
\hline Taxable income & & $\$ 20,414$ & $\$ 21,122$ & $\$ 21,856$ & $\$ 22,617$ & $\$ 23,407$ & $\$ 24,226$ & $\$ 25,077$ \\
\hline Income Tax (25\%) & & $\$ 5,104$ & $\$ 5,281$ & $\$ 5,464$ & $\$ 5,654$ & $\$ 5,852$ & $\$ 6,057$ & $\$ 6,269$ \\
\hline Net Income & & \$ 15,311 & $\$ 15,842$ & $\$ 16,392$ & $\$ 16,963$ & $\$ 17,555$ & $\$ 18,170$ & $\$ 18,808$ \\
\hline
\end{tabular}

Table 7. Net Cash Flow of the Project

\begin{tabular}{|c|c|c|c|c|c|c|c|c|}
\hline Cash flow statement & & \multirow[t]{2}{*}{1} & \multirow[t]{2}{*}{3} & \multirow[t]{2}{*}{5} & \multirow[t]{2}{*}{6} & & \multirow[b]{3}{*}{$\$ 18,170$} & \multirow[b]{3}{*}{$\$ 18,808$} \\
\hline \multicolumn{2}{|l|}{ Operational Activities } & & & & & & & \\
\hline Net Income & & $\$ 15,311$ & $\$ 15,842$ & $\$ 16,392$ & $\$ 16,963$ & $\$ 17,555$ & & \\
\hline Investment activities & $\$(28,922)$ & & & & & & & \\
\hline \multicolumn{9}{|l|}{ Equipment / Machinery } \\
\hline \multicolumn{9}{|l|}{ Redemption value } \\
\hline \multicolumn{9}{|l|}{ Rate of tax on profits } \\
\hline Working Capital & $\$(-6,497)$ & & & & & & & \\
\hline Financial Activities & $\$ 7,500$ & & & & & & & \\
\hline \multicolumn{9}{|l|}{ Credit Funds } \\
\hline Payment to Capital & & $\$ 809$ & $\$ 884$ & $\$ 966$ & $\$ 1,055$ & $\$ 1,152$ & $\$ 1,259$ & $\$ 1,375$ \\
\hline Net Cash Flow & $\$(27,919)$ & $\$ 14,502$ & $\$ 14,958$ & $\$ 15,427$ & $\$ 15,908$ & $\$ 16,403$ & $\$ 16,911$ & $\$ 17,432$ \\
\hline
\end{tabular}

Through the following formula we will obtain the $N P V$. To verify the veracity of the data, we performed the calculation of the $N P V$ in the following formula:

$$
N P V=\sum_{n=0}^{N} \frac{C_{n}}{(1+r)^{n}}=O
$$




$$
\begin{aligned}
& N P V=\left[\frac{C_{n} 1}{(1+r)^{\wedge 11}}+\frac{C_{n} 2}{(1+r)^{\wedge 12}}+\frac{C_{n} 3}{(1+r)^{\wedge 13}}+\frac{C_{n} 4}{(1+r)^{\wedge 14}}+\frac{C_{n} 5}{(1+r)^{\wedge 15}}+\frac{C_{n} 6}{(1+r)^{\wedge 16}}+\frac{C_{n} 7}{(1+r)^{\wedge 17}}\right]-0 \\
& N P V=\left[\frac{\$ 14,502}{(1+0.07)^{\wedge 11}}+\frac{\$ 14,958}{(1+0.07)^{\wedge 12}}+\frac{\$ 15.427}{(1+0.07)^{\wedge 13}}+\frac{\$ 15,908}{(1+0.07)^{14}}+\frac{\$ 16,403}{(1+0.07)^{15}}+\frac{\$ 16.911}{(1+0.07)^{16}}+\frac{\$ 17.432}{(1+0.07)^{17}}\right]-27,919 \\
& N P V=[13,553.2710+13,064.8965+12,593.0273 \\
& +11,268.5134+10,855.7735]-27,919 \\
& N P V=[85,166.73103-27,919]=\$ 57,247.73103
\end{aligned}
$$

$$
N P V=\$ 57,247.73
$$

Therefore, in this operation we can say that the $N P V$ equation matches the data obtained through Excel Financial Functions.

\section{Internal Rate of Return (IRR)}

To calculate $I R R$ it is necessary to obtain certain values. Therefore, the following formula below is:

$$
I R R=\sum_{t-1}^{T} \frac{C_{t}}{(1+r)^{t}}-C_{0}
$$

Accordingly:

$$
I R R \text { Approximation }=\sum\left(\frac{\sum \text { Income }}{\sum \text { Expenses }}-1\right) \div 1
$$

From the chart Net Cash Flow: year $1=(\$$ $-27,919)$, year $2=(\$ 14,502)$, year $3=(\$ 14,958)$, year $4=(15,427)$, year $5=(\$ 15,908)$, year $6=(\$ 16,403)$ and year $7=(\$ 17,432)$

IRR Approximation $=\left(\frac{111,541}{27,919}-1\right) \div 7$

IRR Approximation $=(3.995165-1) \div 7$

IRR Approximation $=(2.995165) \div 7$
IRR Approximation $=0.4278880654$

IRR Approximation $=0.43$

Up to this part of financial operation, it has obtained only the starting percentage of the IRR because it's not the real one, according to the information obtained through the financial program the IRR is $52 \%$, nevertheless, we should remember that the IRR forces the NPV to become ZERO. Through the following chart, we can observe the following results for every percentage as 43 which is the initial, the 51, and 52 that have been calculated (Table 8).

In the table we can see the periods in seven years that the project has been programmed and at the same time the different values of $r$ for example:

a) Using $r=43 \%$ the remaining IRR value is $4,709.5055$ is an extremely high value and we have to take into consideration that as the percentage increases, the value decreases or approaches to zero.

b) Using $\mathrm{r}=51 \%$ the value of IRR is considerably reduced to 227.6081 nevertheless we still remember that IRR leads to NPV $=0$ (zero).

c) Using $\mathrm{r}=52 \%$ the IRR value gives us negative - 255.7709 means that the percentage equal to zero is passed

Therefore, to obtain the exact value of IRR, an Interpolation is carried out, is can observed in the following (Fig. 3).

The values that come closest to zero are 0.51 and 0.52. Moreover, the sum of 227.6081 and 255.7709 gives us 483. 379. Where the exact value of IRR is found and the difference between both values which is 0.01 , therefore a rule of three is made to find the value of " $x$ ".

$$
\begin{aligned}
& \mathrm{r}=0.01 \longrightarrow 283.379 \\
& \mathrm{X}=\quad<-227.6081 \\
& x=\frac{227.6081 * 0.01}{483.379}
\end{aligned}
$$

Table 8. Results for IRR percentage. Summary table of the operations IRR

\begin{tabular}{|c|c|c|c|c|c|}
\hline Year & Net Cash Flow & Formula & $\mathrm{r}=43 \%$ & $\mathrm{r}=51 \%$ & $\mathrm{r}=52 \%$ \\
\hline 1 & 14502 & $14502 /(1+\mathrm{r})^{\wedge 1}$ & 10141.2587 & 9603.97351 & 9540.78947 \\
\hline 2 & 14848 & $14848 /(1+\mathrm{r})^{\wedge 2}$ & 7260.99076 & 6511.995088 & 6426.5928 \\
\hline 3 & 15427 & $15427 /(1+\mathrm{r})^{\wedge 3}$ & 5275.61831 & 4480.749218 & 4392.89392 \\
\hline 4 & 15908 & $15908 /(1+\mathrm{r})^{\wedge 4}$ & 3804.27088 & 3059.903942 & 2980.17132 \\
\hline 5 & 16403 & $16403 /(1+\mathrm{r})^{\wedge 5}$ & 2743.10921 & 2089.481587 & 2021.64709 \\
\hline 6 & 16911 & $16911 /(1+\mathrm{r})^{\wedge 6}$ & 1977.66654 & 1426.617693 & 1371.22197 \\
\hline 7 & 17432 & $17432 /(1+\mathrm{r})^{\wedge 7}$ & 1425.59103 & 973.8870393 & 929.912534 \\
\hline & & & 32628.5055 & 28146.6081 & 27663.2291 \\
\hline & 27,919 & IRR & 4709.5055 & 227.6081 & -255.7709 \\
\hline
\end{tabular}




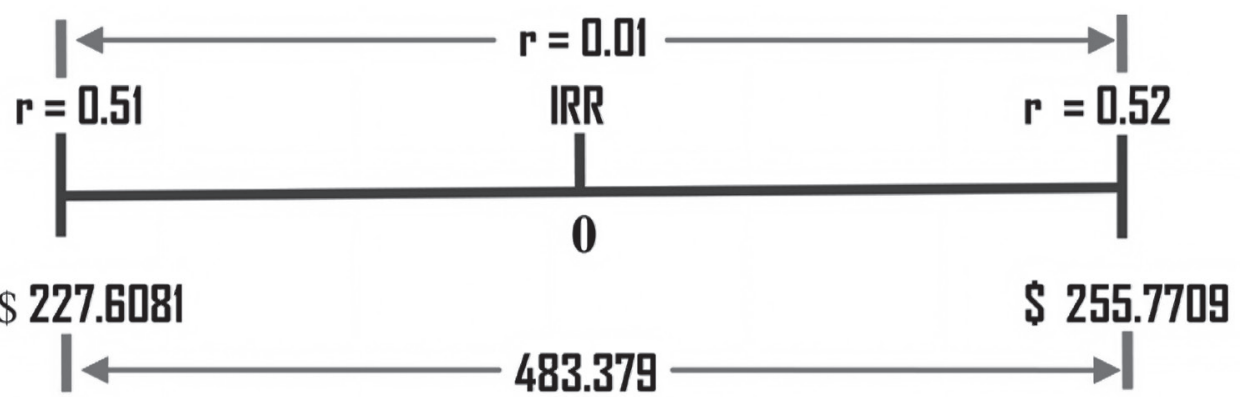

Fig. 3. Value of Internal Rate of Return (IRR).

$$
\begin{gathered}
X=4.7086882 \times 10^{-03} ; X=0.004708688214 \\
\text { IRR }=0.51+0.004708688214 \\
\text { IRR }=0.514708688214
\end{gathered}
$$

$$
\mathrm{IRR}=51.47 \%
$$

To verify the veracity of the data, we performed the calculation of the IRR in the following formula.

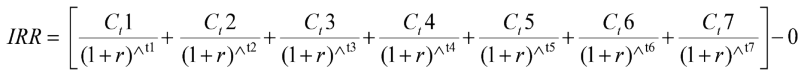

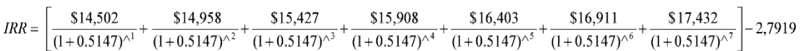

$$
I R R=27,919-27,919
$$

$$
I R R=0(\text { Zero }) \text { when the rate is } 51.47 \%
$$

We can conclude that the IRR of $51.47 \%$ per annum; it tells us that: for the money invested it will recover on average $51.47 \%$ each year and for every dollar invested, it will get back approximately $\$ 0.52$ cents (Table 9).
We can conclude that the IRR of $51.47 \%$ per annum; it tells us that: for the money invested it will recover on average $51.47 \%$ each year and for every dollar invested, it will get back approximately $\$ 0.52$ cents.

Profitability Index

The Profitability Index is a useful tool for making decisions in a project, for example:

- If the Profitability Index is higher than 1, it is accepted - $(\mathrm{PI}=>1$ Accepted $)$

- If the Profitability Index is equal 1 , it is indifferent (PI $=1$ Indifferent)

- If the Profitability Index is less than 1 , the project is rejected (PI $=<1$ Rejected)

The data was tabulated and calculated through the financial formula, as can be observed in the following table, the result was 3.047052287 it means the Profitability Index is higher than " 1 ", Therefore, the project is accepted (Table 10).

To obtain the Profitability Index it is necessary to calculate with the following formula.

$$
P I=\frac{\sum_{t=1}^{n} \frac{C F_{t}}{(1+r)^{t}}}{I}
$$

Table 9. Summary table of the operations IRR

\begin{tabular}{|c|c|c|c|c|c|c|}
\hline Year & Net Cash Flow & Formula & $\mathbf{r}=43 \%$ & $\mathbf{r}=51 \%$ & $\mathbf{r}=52 \%$ & $\mathbf{r}=51.47 \%$ \\
\hline 1 & 14502 & $14502 /(1+\mathrm{r})^{\wedge 1}$ & 10141.2587 & 9603.97351 & 9540.78947 & 9574.1731 \\
\hline 2 & 14848 & $14848 /(1+\mathrm{r})^{\wedge 2}$ & 7260.99076 & 6511.995088 & 6426.5928 & 6472.49992 \\
\hline 3 & 15427 & $15427 /(1+\mathrm{r})^{\wedge 3}$ & 5275.61831 & 4480.749218 & 4392.89392 & 4439.16823 \\
\hline 4 & 15908 & $15908 /(1+\mathrm{r})^{\wedge 4}$ & 3804.27088 & 3059.903942 & 2980.17132 & 3022.89994 \\
\hline 5 & 16403 & $16403 /(1+\mathrm{r})^{\wedge 5}$ & 2743.10921 & 2089.481587 & 2021.64709 & 2057.26462 \\
\hline 6 & 16911 & $16911 /(1+\mathrm{r})^{\wedge 6}$ & 1977.66654 & 1426.617693 & 1371.22197 & 1400.26275 \\
\hline 7 & 17432 & $17432 /(1+\mathrm{r})^{\wedge 7}$ & 1425.59103 & 973.8870393 & 929.912534 & 952.929648 \\
\hline & & & 32628.5055 & 28146.6081 & 27663.2291 & 27919.1982 \\
\hline & 27,919 & $\mathbf{I R R}$ & $\mathbf{4 7 0 9 . 5 0 5 5}$ & $\mathbf{2 2 7 . 6 0 8 1}$ & $\mathbf{- 2 5 5 . 7 7 0 9}$ & $\mathbf{0}$ \\
\hline
\end{tabular}


Table 10. The data tabulated and calculated through the financial results.

\begin{tabular}{|c|c|c|c|}
\hline Year & Net Cash Flow & Formula & PI \\
\hline 1 & 14502 & $14502 /(1+0.07)^{\wedge} 1$ & 12968.81824 \\
\hline 2 & 14848 & $14848 /(1+0.07)^{\wedge} 2$ & 12593.02735 \\
\hline 3 & 15427 & $15427 /(1+0.07)^{\wedge} 3$ & 12136.13703 \\
\hline 4 & 15908 & $15908 /(1+0.07)^{\wedge} 4$ & 11695.1123 \\
\hline 5 & 16403 & $16403 /(1+0.07)^{\wedge} 5$ & 11268.51335 \\
\hline 6 & 16911 & $16911 /(1+0.07)^{\wedge} 6$ & 10855.7735 \\
\hline 7 & 17432 & $17432 /(1+0.07)^{\wedge} 7$ & 85070.6528 \\
\hline
\end{tabular}

Moreover, to verify the veracity of the data, we performed the calculation using this formula:

The PI (Profitability Index) $=$

$$
\begin{gathered}
P I=\frac{\frac{C_{F} 1}{(1+r)^{\wedge 1}}+\frac{C_{F} 2}{(1+r)^{\wedge 2}}+\frac{C_{F} 3}{(1+r)^{\wedge 3}}+\frac{C_{F} 4}{(1+r)^{\wedge 4}}+\frac{C_{F} 5}{(1+r)^{\wedge 5}}+\frac{C_{F} 6}{(1+r)^{\wedge 6}}+\frac{C_{F} 7}{(1+r)^{\wedge 7}}}{I} \\
P I=\left[\frac{\$ 14,502}{(1+0.07)^{\wedge^{1}}}+\frac{\$ 14,958}{(1+0.07)^{\wedge^{2}}}+\frac{\$ 15,427}{(1+0.07)^{3^{3}}}+\frac{\$ 15,908}{(1+0.07)^{\wedge^{4}}}+\frac{\$ 16,403}{(1+0.07)^{\varsigma^{5}}}+\frac{\$ 16,911}{(1+0.07)^{\wedge^{6}}}+\frac{\$ 17,432}{(1+0.07)^{\wedge}}\right] \div 27,919
\end{gathered}
$$$$
P I=[13,553 \times 2710+13,064 \times 8965+12,593 \times 0273+12,136 \times 3703+11,695 \times 1123+11,268 \times 5134+10,855 \times 7735]+27,919
$$

$$
P I=85,070.6528 \div 27,919
$$

$$
P I=3.047052287
$$

Therefore, we can conclude that the PI equation matches with the data obtained through Excel Financial Functions. Accordingly, the result was 3.047052287.

To obtain the expected benefits, according to this case of study, $10 \%$ of the total population of El Salvador consumes mushrooms, this represents only the locations were taken for the research which are Santa Tecla and Antiguo Cuscatlán, this percentage can generate $\$ 182,820.99$ US per month, that's if the mushrooms are sold in the first crops at a price of $\$ 5.25$ per pound, the price can increase gradually according to the demand, the season and the competition in the market. Based on this, the expected internal rate of return (IRR) of $51.47 \%$ per year, it can be concluded that the money invested will be recovered at a rate, on average, of $51.47 \%$ each year. Therefore, for every $\$ 1.00$ US dollar invested approximately $\$ 0.52$ will be returned.

\section{Conclusions}

This case of study sought to analyze the financial feasibility and sustainability of the project, with a mitigation approach, using the solid waste from the coffee agro-industry in order to produce Oyster
Mushroom (Pleurotus Ostreatus). In addition, implementing this project, we become the first to venture into this market segment through production (substrate) because there is few knowledge of this alternative technology, which deals with of breaking agricultural paradigms rooted in the culture of the Salvadoran coffee producers, which mitigates and compensates at the same time the environmental impact generated by the coffee agribusiness, by reusing these biomass and renew it as substrate source (by-product) for $P$. Ostreatus productions. Further, with the start-up of this agro-industrial project, we improved the national economy due to the generation of new sources of work, decreasing the imports of this product. Moreover, one of the main components of this project is the physical construction of two greenhouses for daily production. According to the results, this project is feasible, as there will be sufficient supplies to carry out as raw material, infrastructure, land, and human resources available to carry out the cultivation of oyster mushrooms at the agro-industrial level. Finally, the financial analyses obtained through: $N P V=\$ 57,247.73, I R R=0$ (zero) when the rate is $51.47 \%$ and $P I>1=3.04705228$, shown basically the acceptability and feasibility of this case of study, evidencing that the project is economically profitable.

\section{Acknowledgements}

The authors would like to thank anonymous reviewers for their suggestions and insights, which helped considerably to improve the presentation of our work. Moreover, we appreciate the Faculty of "Agricultura e Investigación Agrícola", Jose Matias Delgado University for the information and data sets used in this study; special acknowledgement to Phetvilay Panyada who helped us in the details of the manuscript. 


\section{Conflict of Interest}

The authors declare no conflict of interest.

\section{References}

1. CRUZ D., LÓPEZ DE LEÓN E., PASCUAL L.F., BATTAGLIA M. Technical guide for the production of edible mushrooms of the species (Pleurotus ostreatus). Journal of Agriculture and Environment for International Development. 104 (3/4), 150, 2010.

2. LOPEZ J.C.C, BHAKTIKUL K. Cultivation of Oyster Mushroom (Pleurotus Ostreatus (Jacq.) P. Kumm.) Using Coffee Waste and Pulp to Mitigate Caffeine and Pulp Related Pollution. Bangladesh Journal of Botany. 47 (4), 888, 2018.

3. KILIAN B., JONES C., PRATT L., VILLALOBOS A. Is Sustainable Agriculture a Viable Strategy to Improve Farm Income in Central America? A Case Study on Coffee. Journal of Business Research, 59 (3), 324, 2006.

4. VALVERDE M.E., HERNANDÉZ-PERÉZ T., PAREDESLÓPEZ O. Edible Mushrooms: Improving Human Health and Promoting Quality Life. International Journal of Microbiology. 2015, 1, 2015.

5. NAKALEMBE I. Comparative nutrient composition of selected wild edible mushrooms from two agro-ecological zones, Uganda. Springer Plus. 4 (433), 4, 2015.

6. ADI A.J., NOOR Z.M. Waste recycling: Utilization of coffee grounds and kitchen waste in vermicomposting. Bioresource Technology. 100 (2), 1029, 2009.

7. HAILE M. Integrated volarization of spent coffee grounds to biofuels. Biofuels Research journal, 2, 67, 2014.

8. NOSEK R., TUN M.M., JUCHELKOVA D. Energy Utilization of Spent Coffee Grounds in the Form of Pellets. Energies. 13 (5), 6, 2020.

9. SOMNUK K., EAWLEX P., PRATEEPCHAIKUL G. Optimization of coffee oil extraction from spent coffee grounds using four solvents and prototype-scale extraction using circulation process. Agriculture and Natural Resources, 51 (3), 184, 2017.

10. CHALA B., OECHSNER H., LATIF., MÜLLER J. Biogas Potential of Coffee Processing Waste in Ethiopia. Sustainability. 10 (12), 14, 2018.

11. PHROMMARAT B. Life Cycle Assessment of Ground Coffee and Comparison of Different Brewing Methods: A Case Study of Organic Arabica Coffee in Northern Thailand. Environment and Natural Resources Journal. 17 (2), 102, 2019.

12. GIRALDI-DÍAZ M.R., MEDINA-SALAS L.D., CASTILLO-GONZÁLEZ E., LEÓN-LIRA R. Environmental Impact Associated with the Supply Chain and Production of Grounding and Roasting Coffee through Life Cycle Analysis. Sustainability. 10 (12), 17, 2018.

13. ADEDOKUN O.M., Oyster mushroom: exploration of additional agro-waste substrates in Nigeria. International Journal of Agricultural Research. 9 (1), 58, 2014.

14. ROSMIZA M.Z., DAVIES W.P., ROSNIZA AZNIE C.R., JABIL M.J., MAZDI M. Prospects for Increasing Commercial Mushroom Production in Malaysia: Challenges and Opportunities. Mediterranean Journal of Social Sciences. 7 (1), 412, 2016.

15. SEKAN A.S., MYRONYCHEVA O.S., KARLSSON O., GRYGANSKYI A.P., BLUME Y. Green potential of Pleurotus spp. in biotechnology. PeerJ. 27, 2019.
16. TOLERA K.D., ABERA S. Nutritional quality of Oyster Mushroom (Pleurotus Ostreatus) as affected by osmotic pretreatments and drying methods. Food Science \& Nutrition. 5 (5), 992, 2017.

17. CASTILLO A.B.E., PARADA JACO R.Y. Mushrooms of El Salvador, Plant Parasitology Lab, Editor, Ministry of Agriculture EL Salvador: El Salvador. p. 9, 2013.

18. CASTILLO A.B.E., PARADA JACO R.Y. Mushrooms of El Salvador, Plant Parasitology Lab, Editor, Ministry of Agriculture EL Salvador: El Salvador. 9, 2013.

19. HART M.M., KLIRONOMOS J.N. Diversity of arbuscular mycorrhizal fungi and ecosystem functioning, in Mycorrhizal ecology. Springer. 240, 2003.

20. POWELL J.R., RILLIG M.C.J.N.P. Biodiversity of arbuscular mycorrhizal fungi and ecosystem function. New Phytologist Foundation. 220 (4), 1072, 2018.

21. SUBHAN M., FARYAL R., MACREADIE I.J.J.O.F. Exploitation of Aspergillus terreus for the production of natural statins. Journal of Fungi MDPI. 2 (2), 8, 2016.

22. ZHANG Y., GENG W., SHEN Y., WANG Y., DAI YU-CHENG. Edible mushroom cultivation for food security and rural development in China: bio-innovation, technological dissemination and marketing. Sustainability. 6 (5), 2970, 2014

23. HANAFI F.H.M., REZANIA S., TAIB M. S., Md-DIN M. F., YAMAUCHI M., SAKAMOTO M., HARA H. PARK J., EBRAHIMI S. S. Environmentally sustainable applications of agro-based spent mushroom substrate (SMS): an overview. Journal of Material Cycles and Waste Management. 20 (3) 1391, 2018.

24. MARAVEAS C.J.S. Environmental Sustainability of Greenhouse Covering Materials. Sustainability. 11 (21), 6129, 2019.

25. VOX G., TEITEL M., PARDOSSI A., MINUTO A., TINIVELLA F., SCHETTINI E. Sustainable greenhouse systems. Sustainable Agriculture: Technology, Planning and Management. 14, 2010.

26. BOATENG A. The impact of planning on successful project implementation: a case of GCB bank data scrub project. Unpublished Thesis of University of Cape Coast. 2015.

27. BAKER M., WURGLER J., YUAN Y.J.J.O.F.E. Global, local, and contagious investor sentiment. Journal of Financial Economics. 104 (2), 286, 2012.

28. RYU D., KIM H., YANG H.J.A.E.L. Investor sentiment, trading behavior and stock returns. Applied Economics Letters. 24 (12), 828, 2016.

29. AL-GHAZZAWI A.M. Pricing Decisions and Borrowing Costs under International Accounting Standard 23 in Jordanian Industrial Corporations. Research Journal of Finance and Accounting. 8 (6), 52, 2017.

30. BARATI A.A., FOROUZ A. Cash Flow and Profit Effect on the Value of the Companies during Different Stages of their Life Cycle. International Journal of Scientific Study. 5 (4), 226, 2017.

31. GURAU M.A. The Use of Profitability Index in Economic Evaluation of Industrial Investment Projects. Proceedings in Manufacturing Systems. 7 (1), 57, 2012.

32. JAMES R. C., CARLO A. M. Measuring the inadequacy of IRR in PFI schemes using profitability index and AIRR. Munich Personal RePEc Archive. 4, 2016.

33. SVEN-OLOV D., HARTWIG F. What Determines the Use of Capital Budgeting Methods? Evidence from Swedish Listed Companies. Journal of Finance and Economics. 2 (4), 103, 2014. 